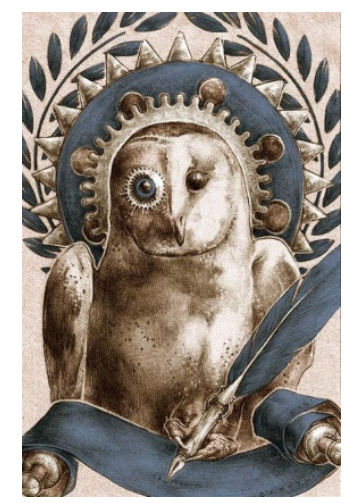

Intelligere, Revista de História Intelectual

vol. 1, no 1 , dez.2015

ARTIGOS - ARTICLES

As vidas de uma vida americana

A Autobiografia de Benjamin Franklin e a ideia de identidade

pessoal

\author{
Joyce E. Chaplin \\ History Department \\ Harvard University \\ chaplin@fas.harvard.edu
}

tradução de Raquel Krempel

Como citar este artigo: Chaplin, Joyce E. "As vidas de uma vida americana - A autobiografia de Benjamin Franklin e a ideia de identidade pessoal". Traduzido por Raquel Krempel. Intelligere, Revista de História Intelectual, vol. 1, nº1, p. 34-45. 2015. Disponível em <http://revistas.usp.br/revistaintelligere>. Acesso em $\mathrm{dd} / \mathrm{mm} /$ aaaa.

Resumo: recorrendo aos campos da história dos impressos e da história da ciência - dois campos de importância indiscutível para entender Benjamin Franklin, o impressor da Filadélfia, e Benjamin Franklin, o famoso experimentador elétrico - este ensaio sugerirá que as memórias de Franklin são evidência de que ele pensou sobre si mesmo como encarnado em ações (como ele tinha se apresentado ao mundo, através de experimentos científicos) e como identificado em relação a outras pessoas, como ele tinha sido por muito tempo, como um colaborador em diversos projetos e como um correspondente. Isso é diferente do seu sentido desencarnado e individualista que a maioria das edições de sua autobiografia, como uma simples narrativa, lhe deram. Edições mais complexas e com diversos textos podem ser ao menos igualmente válidas, sobretudo para mostrar como ideias de identidade pessoal, nesse ponto da história, eram coletivas e encarnadas.

Palavras-chave: Benjamin Franklin - biografia - identidade pessoal - história dos impressos - história da ciência - história intelectual.

\title{
The lives of an American life - The Autobiography of Benjamin Franklin and the idea of personal identity
}

\begin{abstract}
Drawing upon the fields of the history of print and the history of science - two fields of undoubted significance for understanding Benjamin Franklin the Philadelphia printer and Benjamin Franklin the famous electrical experimenter - this essay will suggest that Franklin's memoirs are evidence that he thought of himself as embodied in actions (as he had introduced himself to the world, through scientific experiments) and as identified in relation to other people, as he had for so long been as a collaborator on various projects and as a correspondent. This is different from the disembodied and individualistic sense of him that most editions of his autobiography as a simple narrative have given. More complicated and multi-text editions may be at least as valid, not least in showing how ideas of personal selfhood, at this point in history, were collective and embodied.
\end{abstract}

Intelligere, Revista de História Intelectual revistas.usp.br/revistaintelligere 
Keywords: Benjamin Franklin - biography - personal identity - history of print - history of science - intellectual history.

Benjamin Franklin não foi o primeiro americano a documentar a própria vida, tampouco foi incomum o registro de sua vida. No final do século dezoito, dentro do ambiente das colônias britânicas, a autodocumentação por meio da narrativa pessoal era uma prática bem estabelecida, e a publicação dos resultados tinha se tornado comum. Mas a "Autobiografia" de Franklin se destaca porque se tornou o primeiro best-seller americano. Ao contrário de outras memórias dos primórdios da história americana, ela tem sido parte do cânone da literatura americana desde o século XIX e, bem ou mal, mesmo que outros exemplos de escrita de vida americana ou britânica do Atlântico dessa época tenham compartilhado os holofotes, a "Autobiografia" de Franklin manteve uma presença persistente. Sua narrativa pode ser mais incomum, no entanto, não por causa de sua fama, mas porque nunca foi concluída. Ela é a obra inacabada mais amplamente lida no mundo, e é bastante interessante que, dentre todos os livros do mundo, seja uma autobiografia que ocupe essa posição. Porque as memórias e o seu autor são famosos, elas são frequentemente citadas como evidência de uma ideia emergente do eu moderno, um caso em que uma pessoa que, apesar de não ser bem nascida, escreveu para identificar-se como o autor (ou autora) de uma vida, compreendendo tanto os fatos que compuseram a vida como as experiências pessoais que tiveram importância acumulada. Mas, no caso do famoso e amplamente citado exemplo de Franklin, ocorre que a ideia embutida de um "eu" é intrigantemente incompleta. ${ }^{1}$

Para tornar as coisas ainda mais interessantes, a obra de Franklin é incompleta em dois sentidos: Franklin nunca completou a narrativa que iniciou, como a história de sua vida, e não há instruções claras existentes sobre quais textos ele queria publicar conjuntamente ou dentro dela, como suplementos para a narrativa. Ao contrário, vários herdeiros de Franklin passaram a ponderar acerca de como ele poderia ter querido que o livro fosse, e todos desde então continuam enfrentando esse desafio. De modo geral, uma resposta simples foi sugerida para o problema. A imensa maioria daqueles que editaram o texto de Franklin publicou a narrativa como uma história independente contendo as memórias declaradas de uma pessoa sobre seu eu anterior; a maioria dos estudiosos que citam a obra a consideram da mesma maneira. $\mathrm{O}$ resultado é uma visão não problematizada da identidade pessoal, na qual Franklin é pensado como tendo pretendido que sua narrativa estabelecesse algo internamente consistente sobre seu eu individual. Embora alguns estudiosos tenham enfatizado a habilidade de Franklin de fazer sua vida (e seu eu) aparecer em aspectos muito particulares, as estratégias dele só destacam a deliberação pela qual essa pessoa moderna em particular apresentou sua identidade pública como de autoria própria.

Estudos mais recentes, contudo, questionam se "identidade" pode ter algum significado para o início da era moderna, e há a preocupação concomitante de que utilizar um conceito de "identidade americana" (como faz uma grande quantidade de obras sobre história e literatura

\footnotetext{
${ }^{1}$ Para o exame - se não obsessão - da geração passada de estudiosos da questão da identidade no mundo Atlântico, ver os ensaios representativos em Nicholas Canny e Anthony Pagden, eds., Colonial Identity in an Atlantic World, 1500-1800 (Princeton: Princeton Univ. Press, 1987); Ronald Hoffman, Mechal Sobel \& Fredrika J. Teute, eds., Through a Glass Darkly : Reflections on Personal Identity in Early America (Chapel Hill, N. C.: Omohundro Institute of Early American History and Culture, 1997); e Robert Blair St. George, ed., Possible Pasts: Becoming Colonial in Early America (Ithaca: Cornell University Press, 2000). Para uma das análises mais atentas do eu e da identidade nos primórdios da era moderna, ver Dror Wahrman, The Making of the Modern Self: Identity and Culture in Eighteenth-Century England (New Haven: Yale University Press, 2004). Para exames influentes da formação textual da identidade, com a autobiografia de Franklin como um exemplo central, ver Larzer Ziff, Writing in the New Nation : Prose, Print, and Politics in the Early United States (New Haven, Conn.: Yale Univ. Press, 1991); Michael Warner, The Letters of the Republic : Publication and the Public Sphere in Eighteenth-Century America (Cambridge, Mass.: Harvard University Press, 19). Ormond Seavey, Becoming Benjamin Franklin: The Autobiography and the Life (University Park, Penn.: Penn. State Univ. Press, 1988), é um exemplo representativo de como os historiadores leem as memórias como o registro de uma vida histórica.
} 
americana) só duplica o problema. Havia realmente, antes dos anos 1800, uma crença comum de que uma pessoa individual tinha um senso estável de identidade? Ou os historiadores impuseram essa ideia a pessoas em um momento da história em que isso teria lhes parecido absurdo? Ideias da época sobre identidade poderiam ter incluído designações firmes de nacionalidade, tais como "americano", ou (para os colonos na América Britânica) "colonial", "crioulo", ou "britânico"? A identidade era um rótulo fixo que uma pessoa vestia como um indivíduo, dentro do qual se sentia inserida? Ou era, em vez, uma série móvel de designações, experimentadas contextualmente e em interação com outros?2

Se a história da identidade pessoal tem sido uma preocupação central para os estudiosos da formação dos Estados Unidos, incluindo historiadores de história intelectual, e se a "Autobiografia" de Franklin é um exemplo frequentemente citado no desenvolvimento do conceito da identidade moderna, então o fato é que esse celebrado exemplar não é de modo algum tão claro em sua concepção original como tendemos a acreditar. A escrita de vida de Franklin constituiu, desde o início, um legado literário confuso. Ele era confuso em muitos sentidos-Franklin não apenas decidiu não deixar instruções claras para a sua disposição final, como também tinha espalhado (ou perdido) alguns dos diferentes segmentos que ele parecia querer inserir ali, o que colocou pressão sobre seus vários herdeiros e admiradores para reconstruir, da melhor maneira que podiam, o que podia ter sido projetado como um compêndio, e não como uma narrativa única.

Esse problema deu ao próprio manuscrito completo sobrevivente da autobiografia, mantido na Huntington Library em San Marino, Califórnia, um status um tanto problemático. Foi ele concebido como uma narrativa independente, tal como tem sido entendido mais recentemente, como uma história bastante legível dos famosos altos e altos do Fundador? Ou Franklin teria pensado a sua narrativa como uma série de longas introduções, ou textos paralelos a ainda outros escritos que ele considerava igualmente valiosos como interpretações dos episódios importantes de sua vida? É difícil descobrir evidência clara tanto para um lado como para o outro. Se Franklin deixou instruções escritas para algum de seus herdeiros literários, elas não vieram à tona. Entretanto, o texto de sua autobiografia sempre incluiu anotações de que alguns documentos poderiam ou deveriam ser inseridos em vários pontos, as quais a maioria dos leitores (e alguns editores) da narrativa simplesmente ignora. Finalmente, duas das publicações de Franklin que poderiam ser consideradas modelos potenciais para a "autobiografia" apontam, sem ajuda, para duas direções completamente diferentes: ou para a envolvente narrativa em primeira pessoa, desprovida de vozes concorrentes, ou então para um compêndio documentário e até mesmo multivocal.

Recorrendo aos campos da história dos impressos e da história da ciência - dois campos de importância indiscutível para entender Benjamin Franklin, o impressor da Filadélfia, e Benjamin Franklin, o famoso experimentador elétrico - este ensaio sugerirá que as memórias de Franklin são evidência de que ele pensou sobre si mesmo como encarnado em ações (como ele tinha se apresentado ao mundo, através de experimentos científicos) e como identificado em relação a outras pessoas, como ele tinha sido por muito tempo, como um colaborador em diversos projetos e como um correspondente. Isso é diferente do seu sentido desencarnado e individualista que a maioria das edições de sua autobiografia, como uma simples narrativa, lhe deu. Edições mais complexas e com diversos textos podem ser ao menos igualmente válidas,

\footnotetext{
${ }^{2}$ Rogers Brubaker e Frederick Cooper, "Beyond 'Identity," Theory and Society, 29 (2000): 1-47; Joyce E. Chaplin, "Expansion and Exceptionalism in Early American History," Journal of American History, 89 (2003); "Creoles in British America: From Denial to Acceptance" em Creolization: History, Ethnography, Theory, ed. Charles Stewart (Walnut Creek, Ca.: Left Coast Press, 2006).
} 
sobretudo para mostrar como ideias de identidade pessoal, nesse ponto da história, eram coletivas e encarnadas. ${ }^{3}$

Franklin escreveu suas memórias durante um momento crítico de transição na escrita de vida, a exposição de uma vida em primeira pessoa, e desse modo ele exemplificou o que muitos outros colonos consideravam como gêneros importantes para explicar eles mesmos. Especificamente, Franklin e seus contemporâneos tinham à sua disposição tanto tradições cristãs de autoabnegação, como exames pós-renascentistas de uma personagem em constante evolução. Contudo, Franklin escreveu um pouco cedo demais para considerar moldar a história de sua vida de acordo com ideias ainda mais novas de um eu interior único e autêntico, e jamais poderemos saber se ele sequer pensou sobre si mesmo nesses termos. ${ }^{4}$

O gênero ocidental mais antigo na tradição de escrita de vida, a confissão religiosa, a crítica do eu como um meio para a redenção espiritual, foi de grande utilidade para muitos dos colonos americanos de orientação espiritual. Muitas vidas de santos cristãos, quer autobiográficas ou biográficas, usaram essa narrativa espiritual clássica, a qual tinha o objetivo de mostrar aos crentes o valor de uma vida exemplar e fazê-los imitá-la. Franklin certamente conhecia as famosas Confissões de Santo Agostinho (e possivelmente as Confissões de JeanJacques Rousseau, que menciona, embora rejeite o gênero). E ele tinha certamente ouvido ou lido muitas elegias puritanas da Nova Inglaterra a indivíduos que tinham levado vidas cristãs exemplares, variações protestantes na longa tradição de confissões espirituais. Em suas próprias memórias, a ênfase de Franklin em sua educação religiosa em Boston, suas reflexões sobre seus erros ou errata, e o seu "Projeto audacioso e árduo de chegar à Perfeição moral" mostram sua dívida com a tradição espiritual na escrita de vida. ${ }^{5}$

Mas a sua narrativa pouco se parece com outros exemplos coloniais que são muito mais investidos de piedade. Agora é uma prática padrão comparar Franklin com Olaudah Equiano, o ex-escravo africano que também escreveu memórias. Embora Equiano fosse mais jovem que Franklin e um convertido ao cristianismo, por isso em certo sentido duplamente distanciado das tradições espirituais dos escritos de vida ocidentais, sua narrativa é muito mais convencional como uma história de luta e redenção cristãs. Também é relevante que Franklin abertamente parodiou gêneros puritanos de autoexame, como em suas famosas cartas "Silence Dogood", nas quais ele escreveu como se fosse uma viúva puritana que estava sempre tentando, e de algum modo sempre falhando, ser humilde diante de Deus e de seus superiores sociais. ${ }^{6}$

\footnotetext{
${ }^{3}$ Sobre a história do livro, da impressão, e da publicação nas colônias (e no mundo Atlântico), ver Warner, Letters of the Republic, Hugh Amory e David D. Hall, eds., The Colonial Book in the Atlantic World (Worcester, Mass.: American Antiquarian Society, 2000); David D. Hall, Ways of Writing: The Politics and Power of Text-Making in Seventeenth-Century New England (Philadelphia: Pennsylvania Univ. Press, 2008). Distingo minha interpretação do manuscrito de Franklin como um legado ambíguo, especialmente suas decorrentes incertezas de publicação, da análise do texto como deliberadamente inacabado, de Douglas Anderson, uma interpretação que ignora a história post-mortem da publicação do texto. Ver Anderson, The Unfinished Life of Benjamin Franklin (Baltimore: Johns Hopkins University Press, 2012).

${ }^{4}$ Sobre a auto-exposição "romântica" que enfatizou um conjunto de experiências interiores altamente individualizadas como relacionadas à identidade, ver Jay Paul, Being in the Text: Self-Representation from Wordsworth to Roland Barthes (Ithaca, N. Y.: Cornell Univ. Press, 1984); Charles J. Rzepka, The Self as Mind: Vision and Identity in Wordsworth, Coleridge and Keats (Cambridge, Mass.: Harvard Univ. Press, 1986).

${ }^{5}$ Sacvan Bercovitch, The Puritan Origins of the American Self (New Haven, Conn.: Yale Univ. Press, 1960); Daniel B. Shea, Spiritual Autobiography in Early America (Princeton: Princeton Univ. Press, 1968); Ruth A. Banes, "The Exemplary Self: Autobiography in Eighteenth-Century America," Biography, 5 (1982), 22639; Kathleen Lynch, Protestant Autobiography in the Seventeenth-Century Anglophone World (New York: Oxford University Press, 2012).

${ }^{6}$ Vincent Carretta, Equiano, the African: Biography of a Self-Made Man (Athens, Ga.: Univ. of Georgia Press, 2005), xiii, 193, 206; Joyce E. Chaplin, “1722: Benjamin Franklin's Silence Dogood Letters," em A New Literary History of America, ed. Greil Marcus and Werner Sollors (Cambridge, Mass.: Harvard Univ. Press, 2009).
} 
De fato, em suas referências constantes à literatura secular, e em sua admissão irônica, quase cômica de suas falhas, Franklin deu um passo estratégico para longe do gênero cristão das confissões. Ele se distanciou da piedade convencional mesmo quando ele valorizava essa qualidade em outras pessoas (e a recomendava em teoria). Ele equilibrou esses remanescentes religiosos com as tradições seculares de autoaprimoramento que tinham caracterizado a escrita de vida desde a Renascença. A criação e a apresentação de uma personagem polida eram objetivos de manuais de conduta nos tempos coloniais, guias que eram normalmente escritos para aconselhar jovens aristocratas e futuros monarcas que herdariam poder e precisavam aprender como projetar autoridade da maneira correta. Nicolau Maquiavel famosamente subverteu esse gênero de espelho-para-príncipes em O Príncipe (1532), que recomendava esperteza e o uso declarado da força, enquanto manuais de conduta mais tradicionais defendiam a misericórdia e a justiça. ${ }^{7}$

O ideal de autoaprimoramento principesco estava, entretanto, se espalhando para o resto da sociedade. Guias de autoajuda logo apareceram para auxiliar as sempre crescentes classes médias. Os guias ensinavam as pessoas a se polirem, para parecerem com as ordens em vigor, através da aquisição de um repertório de hábitos graciosos e itens de consumo caros: boas maneiras à mesa, modos apropriados de falar em público, dançar na moda, ampla leitura, a aquisição de línguas estrangeiras, e vestimentas e móveis para casa apropriados. O desenvolvimentos de guias para a boa vida correu paralelamente com uma profusão geral, pelos séculos XIV e XV, de narrativas em primeira pessoa. De fato, enquanto a escrita de vida continuava a ser dominada pelas histórias de pessoas exemplares ou da elite, membros alfabetizados das classes artesãs (normalmente homens, mas às vezes mulheres) cada vez mais mantinham diários e outras explicações pessoais deles mesmos. ${ }^{8}$

Enfatizo os exemplos desse gênero em desenvolvimento da escrita de vida porque eles chegaram em quantidades abundantes nas colônias britânicas do século XVIII. Franklin não era único em seu entusiasmo pelo gênero de literatura de autoajuda, que foi importado, lido e reimpresso amplamente pelo Atlântico britânico. Como muitos de seus contemporâneos, incluindo George Washington, ele redigiu um programa de autoaprimoramento. Ele foi mais longe que outros autores ao escrever literatura de autoajuda para publicação, tanto na forma de recomendações sinceras ("The Way to Wealth") como de paródias ("How to Make Oneself a Disagreeable Companion"). Ele respondeu ao pedido de alguns amigos, de completar e publicar um ensaio chamado "Art of Virtue", com a decisão, ao contrário, de incorporar seu programa moral à sua história de vida. Às voltas com uma carreira pública progressivamente ocupada, tornada ainda mais ocupada com a Revolução Americana, ele tentou compor uma narrativa clara de si mesmo, do nascimento até o serviço público que, em um círculo vicioso, o mantinha preocupado demais para realmente documentar como e por que ele tinha se tornado tão proeminente. ${ }^{9}$

Franklin escreveu suas memórias em quatro seções em quatro momentos diferentes durante o último quartel de sua vida, começando em 1771, aos 65 anos. Ele escreveu em folhas grandes de papel, tamanho fólio, dobradas ao meio formando páginas que mediam cerca de $25 \mathrm{~cm}$ por $38 \mathrm{~cm}$, aproximadamente as dimensões de um laptop. Ele dividiu cada página longitudinalmente e compôs um esboço inicial em uma metade, deixando o outro lado em

${ }^{7}$ Felix Gilbert, "The Humanist Concept of the Prince and the Prince of Machiavelli," Journal of Modern History, 11 (1939), 449-83.

8 Norbert Elias, The Civilizing Process, trad. Edmund Jephcott (Oxford: Blackwell, 1994); Stephen J. Greenblatt, Renaissance Self-Fashioning: From More to Shakespeare (Chicago: Univ. of Chicago Press, 1980); James Amelang, The Flight of Icarus: Artisan Autobiography in Early Modern Europe (Stanford: Stanford Univ. Press, 1998); Adam Smyth, Autobiography in Early Modern England (New York: Cambridge University Press, 2010).

${ }_{9}$ Richard L. Bushman, The Refinement of America: Persons, Houses, Cities (New York: Knopf, 1992), 30-99; Joyce E. Chaplin, ed., "Benjamin Franklin: A How-to Guide. Catalog of an Exhibition" número duplo do Harvard Library Bulletin, vol. 17, no. 1 (2007). 
branco, para que pudesse fazer notas a si mesmo para adicionar ou alterar o material posteriormente, ou para compor mudanças ao que ele já tinha escrito. ${ }^{10}$

A maioria das páginas, 200 de 230, inclui alterações de um tipo ou de outro, feitas ou logo depois que Franklin compôs o texto original, ou quando ele já tinha passado para eventos posteriores e reconsiderado sua redação original. A página com as alternações mais densas é a primeira, já que Franklin, um escritor realizado, lutou para criar o começo certo para a sua história. Ele começou com uma visão geral da história da família Franklin. Isso deve ter parecido muito alheio ao seu verdadeiro assunto, ele mesmo, porque ele adicionou na margem vários comentários pessoais: seu progresso "da pobreza e obscuridade nas quais nasceu e foi criado, a um estado de riqueza e algum grau de reputação", sua crença de que ele "não deveria ter qualquer objeção contra uma repetição da mesma vida desde o começo", contanto que ele pudesse corrigir seus erros, e sua admissão sincera de que escrever suas memórias gratificaria sua "Vaidade". Ele tomou decisões sobre como moldar a história enquanto avançava. Por exemplo, todos exceto um de seus famosos "errata", os maiores erros de sua juventude, foram primeiramente adições marginais, pensamentos posteriores que ele inseriu depois no fluxo narrativo. Essas pequenas confissões adicionaram muito à história, evitando que ela fosse uma história meramente autocongratulatória dos triunfos subsequentes de Franklin. ${ }^{11}$

As razões de Franklin para escrever suas memórias mudaram ao longo dos quase 19 anos em que ele as compôs. Ele escreveu a primeira das quatro seções (87 páginas manuscritas) no verão de 1771, durante uma visita de duas semanas a seu amigo Jonathan Shipley, Bispo de St. Asaph. Franklin endereçou essa peça de abertura ao seu único (e ilegítimo) filho, William Franklin, mas quando escreveu a seção seguinte ele havia rompido relações com William, que tinha se mantido leal à Grã-Bretanha enquanto seu pai se aliou aos Revolucionários Americanos. Amigos insistiram que Franklin continuasse suas memórias. Quando voltou a escrever, ele pretendia que a história de sua vida se dirigisse a um público mais amplo, a geração nascente de americanos independentes. Naquele momento Franklin estava na França e, liberado de seus deveres como plenipotenciário americano naquele país em 1784 - quando os Estados Unidos tinham conquistado sua independência da Grã-Bretanha - finalmente foi capaz de escrever a segunda parte de suas memórias, um total de 12 páginas, incluindo a lista das treze virtudes pessoais que ele tentou cultivar. (“6. INDÚSTRIA. Não perder tempo... 12. CASTIDADE. Manter relações sexuais raramente, exceto pela saúde ou descendência; nunca por tédio) - isso atraía igualmente tanto aqueles leitores que as viam como objetivos sérios como aqueles que pensavam que Franklin estava aqui novamente parodiando o autoaprimoramento sério.

Franklin tomou uma decisão estratégica, quando voltou à Filadélfia em 1785, de usar seu tempo no mar para esboçar algumas teses científicas, ao invés de continuar escrevendo suas memórias. Ele fez isso para a alegria dos historiadores da ciência, mas para a tristeza de estudiosos de literatura. O serviço público absorveu Franklin mais uma vez quando ele retornou à Filadélfia, em 1785, e foi (um tanto ressentido) varrido para a política, como chefe do governo da Pensilvânia, e como um representante da Pensilvânia na Convenção Constitucional Federal, em 1787.

Em 1788, Franklin se aposentou de vez do serviço público e teve finalmente tempo para escrever a terceira parte de sua narrativa, 119 páginas, a mais longa seção do texto. Mas a sua saúde rapidamente em declínio o interrompeu. Foi impossível para ele compor mais do que uma quarta parte muito curta antes de sua morte, em 1790. Ele estava fraco demais até para pegar sozinho uma caneta, e provavelmente ditou essas últimas 7 páginas ao seu neto até que

10J. A. Leo Lemay \& Paul Zall, eds., The Autobiography of Benjamin Franklin: A Genetic Text (Knoxville: Univ. of Tennessee Press, 1981)..

${ }^{11}$ Ibid.. 
fosse incapaz de continuar até mesmo isso. A narrativa simplesmente termina no meio de 1758. Felizmente, Franklin tinha feito um esboço para a obra inteira, provavelmente quando começou a escrever a sua primeira parte, então temos boa evidência do que ele queria incluir, pelo menos até a época de sua partida da América para a França, em 1776. Contudo, esse preenchimento retrospectivo não leva em conta se Franklin estaria satisfeito ou com o esboço existente, ou com a lista de tópicos que ele tinha pretendido cobrir. As correções e alterações que nós vemos agora no manuscrito podiam ter sido apenas as primeiras de uma série de revisões.

Quando Franklin morreu, legou o manuscrito de sua autobiografia ao mais velho de seus dois netos, William Temple Franklin, o filho ilegítimo de seu rompido filho William, para quem as memórias tinham sido destinadas originalmente. Tendo tirado o garoto do pai monarquista, o avô tinha feito o melhor para terminar a educação de Temple e lançá-lo à vida. Ele tentou lhe arranjar um bom casamento na França e depois conseguir uma boa posição para ele no governo americano, mas nenhum dos dois funcionou. $O$ manuscrito foi mais uma tentativa de dar ao jovem algo de valor que, quando impresso, poderia lhe proporcionar uma pequena renda. Mas Franklin tinha pedido ao seu outro neto, Benjamin Franklin Bache, que fizesse duas cópias das três primeiras partes da autobiografia para mandar a amigos na Inglaterra e na França, para receber suas críticas e pensamentos para revisão. Embora Temple tenha herdado o texto mais completo, e o direito implícito de publicá-lo, ele cometeu um erro estratégico ao contar ao recipiente francês de uma das duas cópias, Louis Guillaume Le Veillard, sobre sua intenção de publicar as memórias juntamente com várias outras obras de seu avô. ${ }^{12}$

Antes que Temple pudesse fazê-lo, uma tradução francesa da primeira parte da autobiografia de seu avô apareceu em Paris em 1791. Le Veillard negou que tivesse dado sua cópia a alguém (talvez alguém tenha interceptado sua correspondência com Temple?) e o editor nunca identificou sua fonte, que ainda é desconhecida. O editor reconheceu que o caso era pelo menos um pouco nefário ao dar a sua obra o título Mémoires de la vie privée de Benjamin Franklin. Uma vie privée, ou vida privada, estava, em 1791, apenas começando a perder sua encarnação indecente original, de um relato ofegante dos detalhes pessoais que uma pessoa famosa não desejaria que o público conhecesse, ou mesmo detalhes inventados que ele ou ela achariam difíceis de refutar, algo bastante semelhante às exposições de tabloide de uma celebridade de hoje em dia. Antes e durante a Revolução Francesa, muitos indivíduos proeminentes, incluindo membros da família real, foram vítimas da publicação de muitas vie privée, que eram propagandas com a intenção de revelar o vício pessoal e a corrupção sistêmica da antiga ordem. Algumas dessas, as quais apareceram na mesma época da edição da autobiografia de Franklin, eram tão difamatórias que os seus verdadeiros impressores não punham seus nomes nas capas. Ao invés disso, as atribuíam à impressora de ninguém menos que Benjamin Franklin! Essa foi uma estratégia inteligente, porque era verossímil. Franklin era, naturalmente, famoso como impressor, e era conhecido por ter dirigido uma pequena editora em sua residência em Passy, França, onde ele publicou materiais para a república americana, que tinha se removido do sistema de governo monárquico, tal como a França tinha acabado de fazer. ${ }^{13}$

A vie privée pirateada de Benjamin Franklin estava muito longe de ser a edição completa e respeitável das memórias de seu avô que Temple Franklin tinha esperado publicar. Pior ainda, duas edições em inglês da autobiografia parcial apareceram em 1793, cada uma delas traduzida a partir da vazada edição francesa. (A esse ponto, a prosa original de Franklin era

\footnotetext{
12 Ibid..

13 Robert Darnton, The Devil in the Holy Water, or the Art of Slander from Louis XIV to Napoleon (Philadelphia: Univ. of Pennsylvania Press, 2010), 422-38; Hector Fleischmann, Les Pamphlets libertin contre MarieAntoinette (Toulouse : Futur luxe nocturne, 2011).
} 
quase irreconhecível.) Enquanto isso, acreditando erroneamente que a sua própria versão do manuscrito podia ter mais erros que as outras duas cópias, Temple a ofereceu a Le Veillard em troca da cópia do francês, sem perceber que o seu original incluía sete páginas finais preciosas que nenhuma outra versão continha. Temple publicou uma edição de seis volumes dos papéis de seu avô, incluindo a versão de Le Veillard da autobiografia, em Londres, entre 1817 e 1818. Essa edição das memórias de Franklin tinha vários defeitos, notavelmente a ausência da seção final. Além disso, Temple suavizou algumas das expressões simples e diretas de seu avô com uma linguagem que teria parecido, aos leitores do século XIX, mais refinada, mais condizente com o estadista nacional que Franklin tinha se tornado no final de sua vida, e menos característica do trabalhador colonial com avental de couro que ele tinha sido um dia. Contudo, essa edição das Memórias da vida e escritos de Benjamin Franklin, apesar de comprometida, apesar de atrasada, era a edição padrão, reimpressa muitas vezes e lida como as "memórias", ou "vida", definitivas de Franklin, primeiro chamada de uma "autobiografia" nos anos de 1840. ${ }^{14}$

O manuscrito original e completo de Franklin ressurgiu em 1867, mas só em 1981 apareceu uma edição impressa precisa baseada nele, quase 200 anos depois da morte de Franklin. Esse tesouro acadêmico foi obra de J. A. Leo Lemay e Paul Zall, que trabalharam na Biblioteca Huntington para produzir um texto genético do manuscrito que indicasse, na forma impressa, a natureza completa da composição de Franklin, incluindo emendas, correções e supressões. Seguindo o exemplo de Lemay e Zall, desde 1981, o ímpeto tem sido de tentar aperfeiçoar, tanto quanto possível, versões impressas da narrativa manuscrita completa. De fato, o aumento do uso do termo "autobiografia" para descrever a narrativa propriamente dita coincidiu com a crescente tendência de publicá-la sozinha, ao invés de como uma parte de um compêndio, como Temple Franklin tinha escolhido fazer. ${ }^{15}$

Conforme já sugeri, ambas as decisões — tanto a narrativa isolada como o compêndio pesado-têm precedentes em dois outros escritos de Franklin, qualquer um dos dois podendo ser visto como um predecessor de suas memórias, em termos de sua popularidade e influência durante a sua vida, isto é, de sua capacidade de transmitir algo central sobre quem Franklin pensava ser e por que ele escreveu o que escreveu.

O primeiro modelo possível é Experiments and Observations on Electricity de Franklin, publicado pela primeira vez em 1751 e expandido em várias edições mais longas dali em diante. Ao designar essa obra como um exemplo de escrita de vida, obviamente quero reivindicar que consideremos uma ampla gama de exemplos para esse gênero. De várias maneiras, a obra científica se assemelha à autobiografia em sua ênfase na experiência pessoal. Em seu formato original, ela era uma coleção de cartas de Franklin, narrativas curtas em primeira-pessoa do que ele tinha feito em vários experimentos. Essa abordagem era convencional na ciência da época, com o observador oferecendo testemunho imediato sobre o que ele (raramente ela) tinha percebido. Conforme Jessica Riskin observou sobre as cartas científicas de Franklin, elas eram especialmente vívidas em suas descrições sobre o que a eletricidade fez ao seu corpo, para dar ao leitor um melhor sentido da eletricidade e do autor, o experimentador inteiramente incorporado, que era um autoexperimentador que testemunhava sobre o que a natureza fazia ao seu corpo. Neste caso, uma ideia do eu não existia puramente dentro de uma mente, mas também no corpus material rodeando a mente que sentia o mundo material ao seu redor. ${ }^{16}$

14 Christopher Hunter, "From Print to Print: The First Complete Edition of Benjamin Franklin's Autobiography," PBSA, 101 (2007): 481-505.

${ }^{15} \mathrm{~J}$. A. Leo Lemay \& Paul Zall, The Autobiography of Benjamin Franklin: A Genetic Text, 1981.

16 Jessica Riskin, Science in the Age of Sensibility: The Sentimental Empiricists of the French Enlightenment (Chicago: University of Chicago Press, 2002), 69-104. Sobre identidade, status e ciência mais amplamente analisados, ver Steven Shapin e Simon Schaffer, Leviathan and the Airpump: Hobbes, Boyle, and the Experimental Life (Princeton: Princeton University Press, 1985), e Shapin, A Social History of Truth: Civility and Science in Seventeenth-Century England (Chicago: University of Chicago Press, 1994). 
Ao longo das diversas edições dos Experiments and Observations, aquela reivindicação pessoal do conhecimento natural foi aumentada pela inclusão de outras cartas de Franklin. Algumas delas eram sobre assuntos não experimentais, como no caso de uma carta na qual ele encorajava um amigo tímido a aprender a nadar, e algumas delas eram sobre questões políticopartidárias, como as "Observations on the Increase of Mankind" de Franklin, que especulava, enquanto a Revolução Americana se aproximava e depois explodia, que os americanos poderiam simplesmente procriar mais que seus degenerados soberanos britânicos. Além disso, ao continuar expandindo e incrementando sua coleção de escritos, Franklin seguiu uma tendência contemporânea na produção de enciclopédias e dicionários, compêndios que apresentavam arsenais de conhecimento para leitores interessados, neste caso, leitores interessados em Franklin e em ciência. ${ }^{17}$

A personagem científica de Franklin, de um autor com uma personalidade individual envolvente e com uma presença corporal amplamente indicada, foi intensificada na edição mais longa dos Experiments and Observations a aparecer na França, sob o título de Oeuvres de $M$. Franklin, produzida em 1769 por um acólito francês, Jacques Barbeu-Dubourg. Como editor da obra, Barbeu-Dubourg providenciou a tradução das principais seções dos Experiments and Observations e solicitou a Franklin alguns ensaios então inéditos, incluindo o trabalho sobre natação. Ele também forneceu uma breve descrição da prática de Franklin de tomar "banhos de ar" nu. O corpo do filósofo foi praticamente exposto. Barbeu-Dubourg escreveu também uma introdução com detalhes pessoais sobre Franklin que nenhuma edição inglesa das cartas científicas tinha feito - ele era, em essência, o biógrafo do autor. Que as pessoas formaram uma imagem de Franklin como um indivíduo particular a partir dessa edição francesa é claro, pela crença errônea, na França, de que o homem de ciência americano era um Quaker. Ele não era, mas Barbeu-Dubourg insinuou que ele fosse, estimulando um mal-entendido generalizado que continua até hoje. ${ }^{18}$

Tudo isso para dizer que Franklin estava acostumado, em 1771, quando começou sua autobiografia, a pôr-se diante do público em uma série de documentos inter-relacionados, em primeira pessoa e às vezes bastante pessoais, a maioria, mas não todos, escritos por ele, a partir dos quais um leitor poderia construir uma narrativa única, se ele ou ela escolhesse fazê-lo. Isso é o que o seu primeiro best-seller internacional tinha feito, com sua história que se desenrola da identificação da eletricidade como uma força material que tinha duas manifestações materiais, positivas e negativas. E, ao se apresentar através da ciência, Franklin estava continuando a chamar a atenção para a atividade que o tinha, inicialmente, tornado internacionalmente interessante. A construção epistolar da obra não seria estranha como um exemplo de escrita de vida, especialmente no século XVIII. Tampouco o seria a inclusão de uma carta ocasional ou de outra contribuição de um outro autor, tal como Barbeu-Dubourg, a fim de aumentar a sensação de correspondência ou conversação que tipificava a sociabilidade do século XVIII. ${ }^{19}$

17 Robert Darnton, The Business of Enlightenment: A Publisbing History of the Encyclopédie, 1775-1800 (Cambridge, Mass.: Harvard Univ. Press, 1979); Frank A. Kafker, ed., Notable Encyclopedias of the Seventeenth and Eighteenth centuries : Nine Predecessors of the Encyclopédie (Oxford: Voltaire Foundation, 1981); Richard Yeo, Encyclopaedic Visions : Scientific Dictionaries and Enlightenment Culture (New York: Cambridge Univ. Press, 2001).

18 Sobre a vida de Franklin na ciência e sua celebridade pública devido a sua obra científica, ver Joyce E. Chaplin, The First Scientific American: Benjamin Franklin and the Pursuit of Genius (New York: Perseus Books, 2006).

${ }^{19}$ Está apenas começando a haver uma literatura sobre o eu, escrita de vida e ciência/natureza. Ver Paul White, "Darwin's Emotions: The Scientific Self and the Sentiment of Objectivity," Isis, 100 (2009), 811 26; Bernhard Kuhn, Autobiography and Natural Science in the Age of Romanticism : Rousseau, Goethe, Thorean (Burlington, Vt.: Ashgate, 2009); Stacy Alaimo, Bodily Natures: Science, Environment, and the Material Self (Bloomington: Ind. Univ. Press, 2010). Sobre sociabilidade, ver John Dwyer e Richard B. Sher, Sociability and Society in Eighteenth-Century Scotland (Baltimore: Johns Hopkins Univ. Press, 1991); Thomas Ahnert e 
Dados os repetidos esforços de Franklin de expressar-se desse modo, não seria de se estranhar que ele pudesse ter desejado que suas memórias fossem publicadas dentro de Oeuvres ou "obras" ainda mais largamente ampliadas. Temple Franklin pode ter tomado a decisão de usar esse formato simplesmente porque ele sabia que seu avô valorizava seus compêndios científicos - e que eles tinham vendido bem na Europa, incluindo Londres, onde a sua própria edição das memórias seria publicada. É possível até mesmo que Temple pudesse estar seguindo instruções de seu avô, quer escritas ou orais.

Quero destacar que Temple Franklin estava também seguindo a lógica do próprio texto. A narrativa começou, afinal, como a carta do patriarca a William Franklin (pai de Temple), e incluía outras obras, tais como outras correspondências, juntamente com o manuscrito de Franklin. Entre a primeira e a segunda seção da narrativa, Franklin tinha inserido cartas de seus amigos Abel James e Benjamin Vaughan, cada um dos quais insistiu que ele completasse as memórias. Ele reproduziu também o texto de um anúncio público que ele tinha lançado em 1755, solicitando vagões que carregassem provisões para as tropas no oeste da Pensilvânia durante a guerra Franco-Indígena. Além disso, em diversos pontos ele anotou onde deveriam ser incluídos documentos que ele não tinha em mãos; esse foi o caso do poema de seu tio, um acróstico do nome "Benjamin Franklin", com as palavras "inseri-lo aqui" na margem. Essa inserção tem sido normalmente fornecida, desde que foi redescoberta em meados do século XIX. Mas ela é tipicamente reproduzida em uma nota de rodapé, não incorporada dentro da narrativa, embora pareça claro que Franklin não a quisesse escondida no fim da página.

$\mathrm{Na}$ maioria das edições publicadas da autobiografia, os editores deixaram como estavam as referências de Franklin a algumas outras obras, sem nenhuma inserção. Quando Franklin narra sua travessia do Atlântico de volta a Filadélfia, na sua juventude, por exemplo, ele se refere ao seu "diário" de viagem e a seu "plano de conduta" para o futuro. Temple Franklin devidamente incluiu o diário inteiro em sua edição das memórias e artigos de Franklin, porque ele tinha uma cópia - de fato, a única versão que sobrevive está nas Memórias impressas que Temple editou. Mas ele não incluiu o plano de conduta que seu avô mencionou. Franklin tinha permitido que um amigo na Filadélfia copiasse aquele plano, e qualquer manuscrito original que possa ter existido está agora perdido. Um fragmento da cópia foi publicado em 1815 e está incluído na edição de Yale dos Papers of Benjamin Franklin. Mas nenhuma dessas inserções, nem o diário nem o plano, apareceu em edições recentes da "Autobiografia". Tampouco aparece um diálogo que Franklin escreveu sobre as virtudes de uma milícia da Pensilvânia, nem o ato resultante da milícia, ambos os quais apareceram na Gentleman's Magazine em 1756, e ambos os quais ele anotou que deveriam ser inseridos no texto.

Considerando a fama e a importância estupendas dos escritos científicos de Franklin durante sua vida, é de se estranhar que ninguém tenha percebido que Temple Franklin poderia estar seguindo o modelo dos Experiments and Observations quando publicou as memórias de seu avô como parte de um compêndio. Penso que isso seja o caso porque a maioria dos editores subsequentes da "autobiografia" de Franklin trabalhavam com literatura, com pouco ou nenhum conhecimento da história da ciência, e, portanto do que era a obra-prima de Franklin durante sua vida, o texto que o fez conhecido do público. Apesar da abertura da escrita de vida a um senso de gênero mais inclusivo, a escrita científica ainda não afetou o campo mais amplo de maneiras muito poderosas. Mas no caso da "autobiografia" de Franklin, provavelmente deveria.

Susan Manning, eds., Character, Self, and Sociability in the Scottish Enlightenment (New York: Palgrave Macmillan, 2011); Scott Breuninger \& David Burrow, eds., Sociability and Cosmopolitanism: Social Bonds on the Fringe of the Enlightenment (London: Pickering and Chatto, 2012). 
Ou talvez não. Um segundo modelo possível para as memórias de Franklin era bem diferente dos escritos científicos. Esse era o extenso "Speech of Father Abraham", uma despedida cômica que Franklin escreveu para o seu último almanaque "Poor Richard", em 1757. Father Abraham é um ancião de aldeia prolixo que apresenta uma longa peroração, que é basicamente uma mistura da sagacidade e sabedoria de Richard Saunders, o pseudônimo usado por Franklin em artigos para almanaques. Publicado de maneira independente, e prolongando-se por centenas de edições, esse divertido ensaio moralista se chamava "The Way to Wealth", em inglês, e "La Science du Bonhomme Richard", em francês, e foi traduzido para ao menos catorze outras línguas. De maneiras ligeiramente diferentes, os dois títulos tornaram clara a expectativa de que Franklin, que estava constantemente se autoaprimorando, estava ele mesmo falando ao leitor, sob seu pseudônimo mais conhecido. Foi para homenagear o diplomata americano que John Paul Jones nomeou seu navio de guerra Bonhomme Richard, que era Benjamin Franklin, e vice versa. ${ }^{20}$

$\mathrm{Na}$ escrita de vida, o uso de um pseudônimo, e até mesmo de uma personagem construída, não é incomum. E, de fato, o status complexo de Franklin como um autor que usava vários pseudônimos atraiu bastante atenção, quer para alertar sobre a sua falta de confiabilidade, quer para elogiar sua criatividade como escritor - às vezes ambos. Houve comparações entre como ele escreveu enquanto disfarçado com outro nome versus como ele escreveu como "Franklin", por isso comparações entre a "Autobiografia" de Franklin e "The Way to Wealth" de Father Abraham são comparações óbvias de se fazer. Pelo menos, a consideração de Franklin como uma personagem multiplamente construída aumentou um alerta para que os historiadores pensem duas vezes antes de usar a autobiografia como uma fonte descomplicada, como uma simples narrativa de fatos ao invés de uma complexa criação literária. E a "vie privee", como o título original da primeira edição francesa das memórias, tinha também enfatizado a capacidade daquele gênero de ser de algum modo não tão completo e verdadeiro, ou até mesmo voluntário.

Uma grande quantidade de edições independentes, breves e legíveis da vida de Benjamin Franklin de fato seguiu o modelo de "Bonhomme Richard"/ "Way to Wealth". A popularidade desse modelo tem sido impulsionada, ao menos em parte, pela demanda de leitores no público geral, mas também pela demanda para cursos universitários, para os quais o que se quer é uma simples brochura da autobiografia. As editoras de livros estão satisfeitas em acomodar as duas fontes de demanda. Eu diria, com base em décadas de experiência pessoal utilizando a autobiografia de Franklin em cursos, quer em cursos menores mais especializados, quer em aulas maiores e mais gerais, que os estudantes tendem, de modo geral, a ler rapidamente ou simplesmente ignorar as indicações dentro da narrativa, para prestar atenção aos outros textos inseridos nela, para melhor apreciar a voz singular de Benjamin Franklin.

Mas o ressurgimento do modelo de compêndio das memórias não é nem impossível nem improvável. Em 2007, o cientista político Alan Houston descobriu na British Library uma das inserções perdidas que Franklin tinha indicado em seu manuscrito. Essa era um pedaço de correspondência de um "Quire Book of Letters" que estava relacionada aos deveres de Franklin de abastecer as tropas coloniais durante a guerra Franco-Indígena. Um "quire" era composto de vinte e quatro a vinte e cinco folhas, aproximadamente. Franklin tinha aparentemente esquecido que o seu estoque de correspondências de guerra era um tanto maior. As quarenta e sete cartas precisaram de trinta e oito páginas para sua reprodução no volume de abril de 2009 do The William and Mary Quarterly. Franklin tinha indicado que ele queria que ao menos dois desses documentos fossem colocados em um ponto na história onde o leitor (de então ou de

20 Patrick Sullivan, "Benjamin Franklin, the Inveterate (And Crafty) Public Instructor: Instruction on Two Levels in 'The Way to Wealth", Early American Literature, 21 (1986/87): 248-59; Claire Lienhardt, "Le Bonhomme Richard de Benjamin Franklin à la conquête de l'Europe : la diffusion d'un best-seller américain en France, en Grande-Bretagne et dans les Etats allemands des années 1770 à 1830," tese de doutorado, Université de Lille III, 2000. 
agora) provavelmente seria desafiado a lembrar do fio da narrativa, após absorver todos os detalhes sobre quais vagões carregaram quais provisões para que lugar, e sobre quem no momento tinha concordado ou discordado com a sua disposição. Além disso, o fluxo lógico seria impedido de outra forma, pelo fato de que esses dois documentos seriam, por sua vez, separados das correspondências do "Quire Book" que os contextualizava mais completamente, a menos que Franklin tivesse decidido que queria que ainda mais dessas cartas fossem inseridas na narrativa. ${ }^{21}$

Isso levanta a questão: Franklin realmente pretendia incluir esses itens, e, se sim, exatamente onde ele disse que eles deveriam ir? Se isso tivesse sido feito, a narrativa pareceria bem diferente. Ela seria composta não só na voz do autor, mas nas múltiplas vozes de seus correspondentes, mais ainda do que tinha sido o caso em seu Experiments and Observations. É revelador que Franklin tenha reclamado várias vezes da inconveniência de estar separado de documentos, deixados na Pensilvânia, que o teriam ajudado a escrever suas memórias, especialmente para reconstruir na forma correta eventos de longa data. Se ele tivesse reencontrado aqueles documentos, e se ele tivesse completado sua narrativa e comandado sua impressão, teria ele tornado as memórias ainda mais multivocais, quebrando seu monólogo, a fim de exibir ainda mais documentos chave da vida sendo narrada? Edições dos seus Experiments and Observations foram ficando cada vez mais longas; um longo conjunto de suas cartas e documentos teria sido um próximo passo natural para o aposentado e famoso homem de letras, talvez ainda mais longo e mais meticuloso do que o que Temple Franklin produziu depois da morte de seu avô.

Admito que provavelmente seria difícil para os devotos de Franklin, ou da escrita de vida, aceitar que a obra em questão poderia ter parecido tão radicalmente diferente. $\mathrm{O}$ necessário vai e vem entre Franklin e um elenco de apoio de outros escritores seria um reajustamento significativo da ideia de uma simples autobiografia do início da América, como de autoria de um eu. Manteria, contudo, que essa seria uma intrigante evidência do compromisso de Franklin com as correspondências e com a sociabilidade na construção de sua vida-um texto característico, e com personalidade, do século XVIII. Um meio termo seria mais parecido com o que Temple Franklin tinha tentado, publicar uma edição longa e até mesmo em múltiplos volumes da vida e cartas, com a narrativa satisfatoriamente ininterrupta, mas com todos os textos paralelos disponíveis, de modo a demonstrar, ainda que de maneira remota, um diálogo entre eles e o monólogo predominante. (Hoje, isso poderia ser feito de maneira mais satisfatória na forma de um texto eletrônico da "Autobiografia", com links embutidos para os outros textos, o que permitiria que diferentes leitores tomassem decisões individuais sobre quais links visitar, e em que ordem.)

Muitas coisas poderiam ser defendidas sobre cada uma dessas soluções; que qualquer uma delas seria de algum modo melhor para manter as intenções originais de Franklin do que poderia ser uma "autobiografia" independente é, é claro, impossível de determinar, a menos que, de algum modo, mais de suas correspondências perdidas venham à tona, especificando exatamente como ele queria que a história fosse afinal. Enquanto isso, o entendimento atualmente dominante das memórias de Franklin como uma declaração de identidade pessoal unívoca ou monoautoral deveria coexistir com a possibilidade igualmente provável de que o autor teria desejado incorporar sua escrita de vida dentro de um conjunto de textos próprios e de outros, de modo a explicar melhor e inteiramente seu eu individual. Embora esse arranjo possa agora nos parecer paradoxal, ele se encaixa com as ideias do século XVIII de identidade como interativa e sociável, e da autoria própria como expressa através de coletividades de textos publicados.

${ }^{21}$ Alan Houston, "Benjamin Franklin and the Wagon Affair of 1755," William and Mary Quarterly, 3d Ser., 66 (2009), 235-86. 